\title{
Differential diagnosis of critical digital ischemia in systemic sclerosis: Report of five cases and review of the literature
}

Dol:

10.1016/j.semarthrit.2016.05.001

\section{Document Version}

Accepted author manuscript

Link to publication record in Manchester Research Explorer

Citation for published version (APA):

Sharp, C., Akram, Q., Hughes, M., Muir, L., \& Herrick, A. (2016). Differential diagnosis of critical digital ischemia in systemic sclerosis: Report of five cases and review of the literature. Seminars in arthritis and rheumatism, 46(2), 209-216. https://doi.org/10.1016/j.semarthrit.2016.05.001

\section{Published in:}

Seminars in arthritis and rheumatism

\section{Citing this paper}

Please note that where the full-text provided on Manchester Research Explorer is the Author Accepted Manuscript or Proof version this may differ from the final Published version. If citing, it is advised that you check and use the publisher's definitive version.

\section{General rights}

Copyright and moral rights for the publications made accessible in the Research Explorer are retained by the authors and/or other copyright owners and it is a condition of accessing publications that users recognise and abide by the legal requirements associated with these rights.

\section{Takedown policy}

If you believe that this document breaches copyright please refer to the University of Manchester's Takedown Procedures [http://man.ac.uk/04Y6Bo] or contact uml.scholarlycommunications@manchester.ac.uk providing relevant details, so we can investigate your claim.

\section{OPEN ACCESS}




\section{Author's Accepted Manuscript}

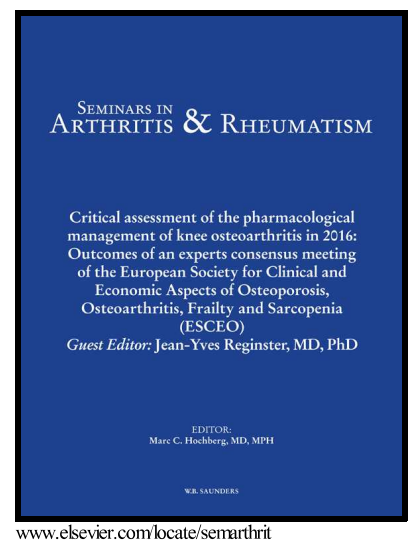

Differential diagnosis of critical digital ischemia in systemic sclerosis: Report of five cases and review of the literature

Charlotte A Sharp, Qasim Akram, Michael Hughes, Lindsay Muir, Ariane L Herrick

PII: $\quad$ S0049-0172(16)30043-9

DOI: $\quad$ http://dx.doi.org/10.1016/j.semarthrit.2016.05.001

Reference: $\quad$ YSARH51051

To appear in: Seminars in Arthritis and Rheumatism

Received date: 2 February 2016

Revised date: 11 April 2016

Accepted date: 9 May 2016

Cite this article as: Charlotte A Sharp, Qasim Akram, Michael Hughes, Lindsay Muir and Ariane L Herrick, Differential diagnosis of critical digital ischemia in systemic sclerosis: Report of five cases and review of the literature, Seminars in Arthritis and Rheumatism, http://dx.doi.org/10.1016/j.semarthrit.2016.05.001

This is a PDF file of an unedited manuscript that has been accepted for publication. As a service to our customers we are providing this early version of the manuscript. The manuscript will undergo copyediting, typesetting, and review of the resulting galley proof before it is published in its final citable form. Please note that during the production process errors may be discovered which could affect the content, and all legal disclaimers that apply to the journal pertain. 


\section{ACCEPTED MANUSCRIPT}

Title: Differential diagnosis of critical digital ischemia in systemic sclerosis:

\section{Report of five cases and review of the literature.}

Authors:

Dr. Charlotte A Sharp ${ }^{1}$, MBChB (Hons), MRCP (UK). Conflicts of interest: none.

Dr. Qasim Akram¹, MBChB, MRCP (UK). Conflicts of interest: none.

Dr. Michael Hughes², MSc, MRCP (UK). Conflicts of interest: none.

Mr.Lindsay Muir ${ }^{3}, \mathrm{MB}, \mathrm{MCh}$ (Orth), FRCS (Orth). Conflicts of interest: none.

Prof. Ariane L Herrick ${ }^{2}, 4$, MD, FRCP. Conflicts of interest: A Herrick has undertaken consultancy work for Actelion and Apricus, spoken at meetings sponsored by Actelion, and received research funding from Actelion.

1Department of Rheumatology, Salford Royal NHS Foundation Trust, Stott Lane, Manchester, M6 8HD, UK

${ }^{2}$ Centre for Musculoskeletal Research, The University of Manchester, Salford Royal NHS Foundation Trust, Manchester Academic Health Science Centre, Manchester, M13 9PT, UK

${ }^{3}$ Department of Orthopaedic Surgery, Salford Royal NHS Foundation Trust, Stott Lane, Manchester, M6 8HD, UK

${ }^{4}$ NIHR Manchester Musculoskeletal Biomedical Research Unit, Central Manchester NHS Foundation Trust, Manchester Academic Health Science Centre. 


\section{ACCEPTED MANUSCRIPT}

Corresponding author and address for reprint requests: Dr Charlotte A Sharp, Department of Rheumatology, Salford Royal NHS Foundation Trust, Stott Lane, M6 8HD, UK

Charlotte.a.sharp@gmail.com

Telephone: +441612755993

Fax: +441612755043

Grant(s) or other financial supporter(s) of the study: nil

\section{Abstract}

1. Objectives: Critical digital ischemia is a rare but serious complication of systemic sclerosis (SSc) and is not always due solely to the non-inflammatory angiopathy which characterises the SSc disease process. Our objective was to illustrate the range of presentations and causes of critical digital ischemia in patients with SSc in order to highlight how optimal management is dependent upon establishing the correct diagnosis.

2. Methods: Five cases exemplifying differential diagnoses were identified and their case notes reviewed in order to extract clinically relevant data and images. A review of the literature was performed in PubMed in English.

3. Results: Causes of critical digital ischemia included typical micro-angiopathic changes and proximal (large vessel) disease. One case highlighted the difficulty of ascertaining whether an inflammatory cause is also present in SSc/SLE overlap syndrome. Two cases demonstrated embolic causes (thromboembolism due to atrial fibrillation, and septic emboli). 


\section{ACCEPTED MANUSCRIPT}

4. Conclusions: Critical digital ischemia in patients with SSc requires thorough investigation in order to avoid missing additional potentially modifiable causes including large vessel disease, inflammation, embolism, infection and paraneoplastic syndromes. A firm evidence base for current medical and surgical interventions is lacking, highlighting the need for further research into the optimum management of this rare but painful, debilitating and limb-threatening complication of SSc.

KEYWORDS: Systemic sclerosis; Scleroderma; Digital vasculopathy; Raynaud's Phenomenon; Critical digital ischemia; Digital ulcer; Embolism; Vasculitis

\section{Introduction}

Critical digital ischemia (ischemia which causes pain at rest and which compromises tissue viability as a result of impaired perfusion/oxygenation, potentially leading to ulceration and gangrene) is a rare but serious complication of systemic sclerosis (SSc). In patients with SSc, this is usually a manifestation of a combination of the progressive microangiopathy and digital artery disease characteristic of SSc, rather than to large (proximal) vessel disease which occurs in patients with atherosclerotic peripheral arterial disease.It is well recognised that in patients with SSc, structural changes occur in both the microvasculature and the digital arteries [1-3], with the microvascular changes being well demonstrated by nailfold capillaroscopy $[4,5]$. However, there may be co-existent disease-related or completely unrelated causes which need to be considered in the patient with SSc presenting with critical digital ischemia, as the overall management of the patient may be influenced by the presence of such factors. Clinical assessment and investigation needs to centre on establishing the underlying cause, in order that treatment is optimised. 


\section{ACCEPTED MANUSCRIPT}

We present a case series of five patients with SSc with severe critical ischaemia leading to tissue necrosis/gangrene, to illustrate these different causes. These causes are potentially treatable, and to miss their diagnosis may result in digital loss/amputation which might otherwise have been prevented. We then review investigation and management, with a focus on recent advances. 


\section{ACCEPTED MANUSCRIPT}

\section{Results (Case Reports)}

\subsection{Patient 1 - Diagnosis for critical ischemia - SSc-related angiopathy}

Patient number 1 was a 62 year old woman who presented with critical ischemia of her right middle finger (Figure 1a). The diagnosis of limited cutaneous SSc (IcSSc) had been made seven years previously after she was referred initially by the orthopaedic surgeons with critical ischemia requiring debridement and amputation of the tip of her left middle finger, debridement of her left ring finger ulcer and a palmar sympathectomy. Histology of the left middle fingertip showed features consistent with SSc, and this along with her recent onset of Raynaud's phenomenon (less than one year) and abnormal nailfold capillaroscopy (Figure 1b) led to the initial diagnosis. She was antinuclear antibody (ANA) positive (titre 1/1000). She had no other manifestations of SSc. She had been a smoker of 5-10 cigarettes per day (cpd) and stopped smoking six months prior to this admission, and was on treatment with nifedipine for her Raynaud's phenomenon.

Immunology testing for both ANCA and antiphospholipid syndrome was unremarkable. Despite optimal medical management including intravenous (IV) antibiotics, IV iloprost infusions and opioid based analgesia, the right middle finger required amputation through the middle phalanx. This healed well (Figure 1c).

Histology from the amputation showed concentric thickening of the vascular intima of one of the digital arteries, with no other pathology found. 


\section{ACCEPTED MANUSCRIPT}

This case illustrates the potential severity of SSc-related digital vascular disease, which can progress to gangrene even with optimal medical management.

\subsection{Patient 2 - Diagnosis for critical ischemia - proximal large vessel disease in combination with SSc-related angiopathy}

Patient number 2 was a 52 year old woman (ex-smoker 20 years before), with a 42 year history of Raynaud's phenomenon and a 13 year history of IcSSc (ANA positive 1/1000, anticentromere positive) and known lower limb peripheral vascular disease (PVD), who presented with tender digital ulcers over the ulnar border of the left little finger nail bed and at the tip of her left ring finger. She also reported an aching, cold sensation over her left arm.

Three years previously she had a successful right popliteal angioplasty after presenting with right forefoot ischemia. At that time right ankle brachial pressure index $(\mathrm{ABPI})$ was reduced at 0.71 . An angiogram demonstrated significant right popliteal arterial disease (Figure 2a). Right popliteal angioplasty with a $4 \mathrm{~mm}$ balloon showed good revascularisation (Figure 2b) with resultant improvement in her symptoms, her ABPI and ulcer healing (Figures $2 \mathrm{c}$ and $2 \mathrm{~d}$ ).

On this admission the distal pulses in her left arm were impalpable and she had a soft subclavian bruit. Testing for ANCA, anticardiolipin antibodies and lupus 


\section{ACCEPTED MANUSCRIPT}

anticoagulant were all negative. Doppler ultrasound scan confirmed significantly reduced pressures on the left compared to the right (left brachial artery systolic pressure $76 \mathrm{mmHg}$, right $103 \mathrm{mmHg}$; left ulnar systolic pressure undetectable, right $135 \mathrm{mmHg}$ ). Computer tomography (CT) angiogram revealed calcified plaque of the superior aspect of the aortic arch with $50 \%$ stenoses of the left common carotid and left subclavian arteries (there was no evidence of inflammation). The ulcers healed well with IV antibiotics, IV iloprost infusions and opioid based analgesia. However, a month later she developed new infected ulcers over her left ring, middle, index and little fingers requiring further courses of IV antibiotics and iloprost which led to healing without the need for further surgical intervention.

Her digital ulceration was felt to be due to a combination of both her digital vasculopathy (from SSc), which responded to medical therapy, and proximal (large) vessel disease. The vascular surgeons felt that revascularisation with angioplasty would carry a substantial risk of stroke and did not undertake any vascular reconstruction.

\subsection{Patient 3 - Diagnosis for critical ischemia - SSc-related angiopathy \\ (and not vasculitis as initially suspected)}

Patient number 3 was a 40 year old woman with a 14 year history of Raynaud's phenomenon and a 13 year history of diffuse cutaneous SSc (dcSSc, antitopoisomerase positive) / systemic lupus erythematosus (SLE) overlap, who 


\section{ACCEPTED MANUSCRIPT}

developed ulceration and critical ischemia of the left middle, ring and little fingers (Figures $3 a$ and $b$ ). She was a lifelong non-smoker. She had good peripheral pulses and upper limb arterial Dopplers were normal. Immunology showed a raised titre of antibodies to dsDNA of $79 \mathrm{u} / \mathrm{ml}(0-7 \mathrm{u} / \mathrm{ml})$ and borderline low complement $(\mathrm{C} 40.14 \mathrm{~g} / \mathrm{l}$ (0.15-0.52g/l). Testing for ANCA, anticardiolipin antibodies and lupus anticoagulant showed no cause for concern. Magnetic resonance (MR) angiography showed no definite occlusion to the left subclavian or proximal axillary arteries. Given the good pulses and normal arterial flow on Dopplers it was unlikely that there would be any lesion amenable to surgery and the risk of formal angiography was felt to outweigh the benefits.

She was treated with IV iloprost infusions, flucloxacillin and opioid based analgesia. High dose prednisone $60 \mathrm{mg}$ was initiated as there was a strong suspicion of an inflammatory component to her disease, given the lupus overlap and high dsDNA, although there were no other clinical features to suggest vasculitis. However this did not result in any improvement and was promptly tapered down. Although her lupus anticoagulant and anticardiolipin antibody were both negative, given the severity and rapid progression of her digital ischemia she was also treated with low molecular weight heparin and subsequently clopidogrel on the assumption that she might have a significant pro-thrombotic tendency. Despite these measures, the fingertip lesions deteriorated and she underwent amputation to the tips of the left middle and ring fingers, five months following the onset of the ischemic episode. Histology showed evidence of SSc but no vasculitis (Figure 3c). 


\section{ACCEPTED MANUSCRIPT}

\subsection{Patient 4 - Diagnosis for critical ischemia - thromboembolism due to atrial fibrillation, against a background of SSc-related angiopathy}

Patient number 4 was a 72 year old woman with an 11 year history of IcSSc (ANA positive $1 / 1000$ nucleolar), paroxysmal atrial flutter/fibrillation, mild left ventricular systolic dysfunction, Barrett's oesophagus and a smoker of $10-20 \mathrm{cpd}$, who was admitted with a five week history of areas of critical digital ischemia involving the left middle and ring fingers. The tips of the left middle and ring fingers were tender to palpation, with well-demarcated necrotic ulcers (Figure 4a). Blood results were unremarkable (Including that she was negative for ANCA, anticardiolipin antibodies and lupus anticoagulant), and the admission electrocardiogram (ECG) showed normal sinus rhythm. However, transthoracic echocardiogram confirmed a dilated left atrium suggestive of chronic atrial fibrillation.

She responded well to IV antibiotic therapy and IV iloprost and was assessed by the cardiology team who agreed that her critical digital ischemia was most likely due to multiple thromboemboli due to paroxysmal atrial fibrillation, although it was not possible to be definite about this. She was then commenced on systemic anticoagulation with warfarin, which had been avoided previously due to gastrointestinal bleeding (from her Barrett's). Within three months the digital ulcers affecting her left middle and ring fingers had completely healed with no new ulceration or necrosis of her fingers (Figure $4 b$ ). 


\section{ACCEPTED MANUSCRIPT}

\subsection{Patient 5 - Diagnosis for critical ischemia - septic embolism}

Patient number 5 was a 54 year old woman with a 10 year history of Raynaud's phenomenon and an 11 year history of IcSSc (ANA negative) / inflammatory arthritis overlap and a smoker of $5 \mathrm{cpd}$, who had major gastro-intestinal involvement of her disease with dysmotility and malabsorption requiring total parenteral nutrition via a tunnelled central venous line. She developed painful lesions to all her fingers (Figures 5a and b) over a two-week period. She was systemically unwell with fevers, nausea, vomiting and dizziness. She was anticardiolipin antibody and lupus anticoagulant negative, and although pANCA was reported as positive this was not thought to be clinically relevant as she was myeloperoxidase (MPO) antibody negative.

She was commenced on IV vancomycin for a line infection following several positive line cultures for coagulase negative Staphylococcus aureus. Septic emboli were suspected due to the presence of multiple bilateral digital infarcts, with appearance and distribution very different from the ischemic lesions more typically seen in SSc because they were small and well demarcated, as well as being very numerous. Therefore a transesophageal echocardiogram was performed. This revealed a $2.3 \mathrm{x}$ $1.3 \mathrm{~cm}$ heterogeneous mass attached to the posterior wall of the right atrium, close to the superior vena cava, which was felt to represent an infected thrombus (Figure 5c). 


\section{ACCEPTED MANUSCRIPT}

The digital infarcts resolved completely following a two-week course of IV antibiotic therapy and anticoagulation, suggesting that they likely resulted from septic emboli. Because of her co-morbidities, frailty and severe difficulty in obtaining IV access, the line was not removed. She remained in hospital and despite recovering from the initial episode of sepsis, she continued to deteriorate. A CT scan of the abdomen two months later demonstrated that her known abdominal aortic aneurysm was likely to have become mycotic and she died as a result of pneumonia shortly afterwards.

\section{Discussion}

Critical digital ischemia represents the most severe and (fortunately) rarest end of the spectrum of digital vasculopathy observed in patients with SSc. This spectrum also includes Raynaud's phenomenon and digital ulceration. As exemplified by Patient 1 , the diagnosis of SSc should always be considered in patients presenting with critical digital ischemia who are not known to have the condition. This applies particularly to those with Raynaud's phenomenon, ANA positivity and puffy fingers, all of which are red flags for the disease $[6,7]$. However, even when a patient has a known diagnosis of SSc, our case series illustrates how clinicians must stay vigilant and maintain a high index of suspicion to detect the presence of 'other' causes, both indirectly SSc-related (e.g. related to vasculitis, especially in patients with overlap syndromes, as suspected in Patient 3) or non-SSc-related (e.g. large [proximal] vessel disease (Patient 2), thromboembolic disease (Patients 4 and 5) and as part of

a paraneoplastic phenomenon [8]). This distinction is absolutely crucial as both the 


\section{ACCEPTED MANUSCRIPT}

management and ultimate prognosis of the critically ischemic digit may differ significantly, as exemplified by our case series.

There are very few reports on frequency of critical ischemia in patients with SSc. In a study of 1,168 patients with SSc attending the Royal Free Hospital, London, critical digital ischemia occurred in $1.6 \%$ patients during 18 months of follow up and $1.4 \%$ progressed to gangrene [9]. Patients are at risk of multiple digital involvement and may progress to irreversible necrosis requiring amputation [9] (Patients 1, 3). Associations between severity of digital ischemia and both anti-centromere $[10,11]$ and anti-32-glycoprotein I [12] antibodies in patients with SSc have been reported. Smoking is a risk factor for severity of digital vascular disease in patients with SSc (Patients 1, 4, 5) $[13,14]$. It has been suggested that patients with SSc have an increased risk of macrovascular proximal (large) vessel disease (Patient 2) compared to patients without SSc $[15,16]$ although this remains controversial [17]. Irrespective of whether or not atherosclerosis is increased in patients with SSc, clinicians must be particularly vigilant for this, because it is likely that the combination of atherosclerosis and SSc-related vascular disease is especially likely to result in critical ischaemia. When atherosclerotic disease does co-exist with SSc (as in Patient 2), a key point is to ensure optimal medical management to reduce risk factors, including smoking cessation, blood pressure control, antiplatelet and statin therapy. Selective involvement of the ulnar artery is well recognised in SSc [18-21] and the digital arteries are commonly involved [22,23]. 


\section{ACCEPTED MANUSCRIPT}

Table 1 lists most of the contributory causes to digital ischemia in patients with SSc. It should be recognised that the distinction between 'SSc-related' and 'non-SScrelated is not clear-cut. For example, antiphospholipid syndrome has (rarely) been reported in SSc [24].

\subsection{Approach to investigation of critical ischemia}

Critical digital ischemia is a true medical emergency which requires both prompt assessment and introduction of treatment in an attempt to save the digit, before the onset of irreversible tissue necrosis. Patient education is therefore absolutely crucial. All patients with SSc should be advised to seek urgent medical attention if any of the digits become permanently discoloured. The United Kingdom Scleroderma Study Group best practice recommendations on digital vasculopathy (including critical digital ischemia), is a useful reference tool for the investigation and management of patients with SSc [25].

The peripheral pulses should be examined early (including formal assessment e.g. by Doppler ultrasound scan if there is any concern) [26] to exclude large (proximal) vessel disease (Patient 2) which may require urgent surgical intervention. Computerised tomography (CT) angiogram and MR angiogram provide more detailed visualisation of the vessels. These both have the advantage of not requiring intra-arterial puncture, and both techniques visualise the lumen and the vessel wall. MR angiography avoids the use of ionizing radiation, but takes longer to perform [27]. Especially if surgery is contemplated then conventional (X-ray) angiography 


\section{ACCEPTED MANUSCRIPT}

may be indicated: however, this is invasive requiring intra-arterial puncture. The key point is for discussion to occur between rheumatologist, vascular surgeon and vascular radiologist, to inform the best approach for each patient [27].

Nailfold capillaroscopy is a key investigation in the diagnosis of SSc, and is therefore useful in patients presenting with critical digital ischemia without a pre-existing diagnosis of SSc (Patient 1). Immunological testing can also aid the diagnosis of the underlying connective tissue disease and may be useful in patients in whom an inflammatory component to their tissue ischemia (e.g. SLE (Patient 3), vasculitis) may be represented by high titres of dsDNA (SLE), ANCA (vasculitis), cryoglobulins (cryoglobulinemia), or low complement C3 and C4 (SLE and cryoglobulinemia). The management of these overlap syndromes is out with the scope of this review, however Patient 3 demonstrates the challenges of determining whether or not critical ischemia is due purely to SSc or a concomitant inflammatory vasculopathy because this distinction is often not possible on clinical grounds, especially if there are no other features of vasculitis. Immunoglobulins and electrophoresis (to look for a paraproteinaemia) and urine dipstix (to look for blood and/or protein, which might indicate systemic vasculitis) should be requested in all patients.

Embolic disease should also be considered in the context of digital ischemia, including assessment for cardiac arrhythmia (Patient 4) with ECG and echocardiogram and, much more rarely (depending on the clinical context), a central septic source of emboli (Patient 5). Thomboembolism more commonly affects lower than upper limbs. If infection is suspected, full blood count, inflammatory markers, cultures of urine, blood, wounds and in-dwelling catheters may aid the diagnosis. 


\section{ACCEPTED MANUSCRIPT}

Thrombophilic states should be investigated with appropriate tests including coagulation studies, lupus anticoagulant, anti-cardiolipin antibodies and anti- $\beta 2$ glycoprotein.

\subsection{Approach to management of critical ischemia}

Management of the critically ischemic digit in patients with SSc is based on a pragmatic and individualised approach, for which a reliable evidence base is lacking. This lack of evidence base, including for surgical options [28], is unsurprising given the rarity of the condition.

The critically ischemic digit may be exceptionally painful; therefore, the patient's analgesia regimen must be reviewed early in the clinical course, and not uncommonly requires opioid based analgesia (Patients 1, 2, 3). Clinicians must have a very low threshold of suspicion to prescribe appropriate antibiotic (either oral or IV) therapy as ischemic digits are often co-infected. Patients who smoke (an intense vasoconstrictor) should be supported in their efforts to stop smoking $[13,14]$ : it is likely that current/recent smoking was a contributory factor to the development of critical ischemia in three of our five patients.

Given that critical digital ischemia is a medical emergency, the patient should be admitted to hospital and intravenous prostanoid therapy initiated without delay, the 


\section{ACCEPTED MANUSCRIPT}

rationale being that this will increase perfusion to the ischemic digit (Patients 1, 2, 3, 4). Subsequently, oral vasodilator therapy should be optimised. Intravenous prostanoids such as iloprost are potent vasodilators and in addition inhibit platelet aggregation. There have been no trials of their use specifically for critical digital ischemia, but their use is well established in patients with SSc-related severe Raynaud's phenomenon, especially those with digital ulceration: they are effective in reducing frequency and severity of Raynaud's attacks and in healing digital ulcers $[29,30]$. Oral vasodilator therapies include calcium channel blockers, angiotensin II receptor antagonists, alpha-blockers and phosphodiesterase type 5 inhibitors, which are being used increasingly in severe Raynaud's phenomenon [31]. If an inflammatory aetiology such as vasculitis is strongly suspected (Patient 3) then treatment with corticosteroids may be warranted. However, this approach requires caution, especially as high dose steroids are a risk factor for renal crisis in patients with SSc [32,33]. Also, as already mentioned, digital lesions are often infected (including with underlying bone infection [34]), and steroids may exacerbate this. Large vessel lesions should be treated with appropriate revascularisation (angioplastic or surgical). Other treatment options utilised by some clinicians (despite the lack of an evidence base to support these interventions) include statin therapy [35], anti-platelet therapy and full systemic anticoagulation (Patient 3). Despite the lack of clinical trial evidence for antiplatelet therapy in SSc-related digital vasculopathy, most clinicians prescribe this in patients with severe digital ischemia, given that platelet activation is well-recognised in SSc [36,37]. Although treatment with the endothelin receptor antagonist bosentan has been shown to reduce the incidence of new digital ulcers (but not to treat existing ones) $[38,39]$, there are no studies of the use of endothelin receptor antagonists in SSc-related critical ischemia. 
If digital necrosis has developed, then surgical intervention (debridement and/or amputation) is usually required [40] although the necrotic digital tissue may spontaneously auto-amputate. Digital palmar sympathectomy [41-43] should be considered in patients with severe ischemia, the aim being to improve blood flow and protect against further injury and dysfunction. Botulinum injection is increasingly being performed worldwide [44-46], the aim being to improve blood flow. The extent of the arterial tree that should be addressed by sympathectomy remains uncertain, with reports of a wide range of suggested surgical strategies [47] Reconstruction of the intrinsic vascular tree of the hand either by vein graft or by arterial graft has been described, as has arterialisation of the venous tree. Recently interest has also been expressed in fat grafting [48]. These interventions should ideally be subjected to the scientific rigor of a randomised clinical trial.

\section{Conclusions}

Critical digital ischemia is a rare, yet potentially serious complication of SSc, which may require amputation of the affected digit. All clinicians involved in the management of SSc need to keep an open mind about the cause of ischemic digits, in order not to miss additional or alternative diagnoses as demonstrated in this case series. The management of any critically ischemic digit includes medical treatment such as antibiotics, vasodilators and analgesia, and surgical options such as 


\section{ACCEPTED MANUSCRIPT}

debridement, amputation and sympathectomy. Depending on the presence of secondary causes, treatment may also include immunosuppression and/or treatment with antiplatelet agents and anticoagulation. Our case series demonstrates the range of presentations and management options in patients with critical digital ischemia and SSc. 


\section{ACCEPTED MANUSCRIPT}

\section{Acknowledgements}

Professor Anthony Freemont, Manchester, UK - provided figure 3c

Dr Peter Woolfson, Salford, UK - provided figure 5c 


\section{ACCEPTED MANUSCRIPT}

\section{References}

1. Campbell PM, LeRoy EC. Pathogenesis of systemic sclerosis: a vascular hypothesis. Sem Arthritis Rheum 1975; 4: 351-68.

2. Rodnan GP, Myerowitz RL,Justh GO. Morphological changes in the digital arteries of patients with progressive systemic sclerosis (scleroderma) and Raynaud's phenomenon. Medicine (Baltimore) 1980; 59: 393-408.

3. Herrick AL. The pathogenesis, diagnosis and treatment of Raynaud phenomenon. Nat Rev Rheumatol 2012; 8: 469-79.

4. Maricq HR, LeRoy EC. Patterns of finger capillary abnormalities in connective tissue disease by 'wide-field' microscopy. Arthritis Rheum 1973; 16: 619-28.

5. Cutolo M, Sulli A, Smith V. Assessing microvascular changes in systemic sclerosis diagnosis and management. Nat Rev Rheumatol 2010; 6: 578-87.

6. Avouac J, Fransen J, Walker UA, Riccieri V, Smith V, Muller C, et al.

Preliminary criteria for the very early diagnosis of systemic sclerosis: results of a Delphi Consensus Study from EULAR Scleroderma Trials and Research Group. Ann Rheum Dis. 2011; 70: 476-81.

7.. Minier T, Guiducci S, Bellando-Randone S, Bruni C, Lepri G, Czirjak L, et al. Preliminary analysis of the very early diagnosis of systemic sclerosis (VEDOSS) EUSTAR multicenter study: evidence for puffy fingers as a pivotal sign for suspicion of systemic sclerosis. Ann Rheum Dis 2014; 73: 2087-93. 


\section{ACCEPTED MANUSCRIPT}

8.. Poszepczynska-Guigné E, Viguier M, Chosidow O, Orcel B, Emmerich J, Dubertret L. Paraneoplastic acral vascular syndrome: epidemiologic features, clinical manifestations, and disease sequelae. J Am Acad Dermatol 2002; 47: 4752.

9. Nihtyanova SI, Brough GM, Black CM, Denton CP. Clinical burden of digital vasculopathy in limited and diffuse cutaneous systemic sclerosis. Ann Rheum Dis 2008; 67: 120-3.

10. Wigley FM, Wise RA, Miller R, Needleman BW, Spence RJ. Anticentromere antibody as a predictor of digital ischemic loss in patients with systemic sclerosis. Arthritis Rheum 1992; 35: 688-93.

11. Herrick AL, Heaney M, Hollis S, Jayson MIV. Anticardiolipin, anticentromere and anti-Scl-70 antibodies in patients with systemic sclerosis and severe digital ischemia. Ann Rheum Dis 1994; 53: 540-2.

12. Boin F, Franchini S, Colantuoni E, Rosen A, Wigley FM, Casciola-Rosen L. Independent association of anti- $\beta 2$-glycoprotein I antibodies with macrovascular disease and mortality in scleroderma patients. Arthritis Rheum 2009; 60: 2480-9. 


\section{ACCEPTED MANUSCRIPT}

13. Harrison BJ, Silman AJ, Hider SL, Herrick AL. Cigarette smoking as a significant risk factor for digital vascular disease in patients with systemic sclerosis. Arthritis Rheum 2002; 46: 3312-6.

14. Hudson M, Lo E, Lu Y, Hercz D, Baron M, Steele R. Cigarette smoking in patients with systemic sclerosis. Arthritis Rheum. 2011; 63: 230-8.

15. Ho M, Veale D, Eastmond C, Nuki G, Belch J. Macrovascular disease and systemic sclerosis. Ann Rheum Dis 2000; 59: 39-43.

16. Caramaschi P, Biasi D, Caimmi C, Barausse G, Sabbagh D, Tinazzi I et al. Digital amputation in systemic sclerosis: prevalence and clinical associations. A retrospective longitudinal study. J Rheumatol 2012; 39: 1648-53.

17. Soriano A, Afeltra A, Shoenfeld Y. Is atherosclerosis accelerated in systemic sclerosis? Novel insights. Curr Opin Rheumatol. 2014; 26: 653-7.

18. Taylor MH, McFadden JA, Bolster MB, Silver RM. Ulnar artery involvement in systemic sclerosis (scleroderma). J Rheumatol 2002; 29: 102-6. 


\section{ACCEPTED MANUSCRIPT}

19. Park JH, Sung YK, Bae SC, Song SY, Seo HS, Jun JB. Ulnar artery

vasculopathy in systemic sclerosis. Rheumatol Int 2009; 29: 1081-6.

20. Higgins JP, McCLinton MA. Vascular insufficiency of the upper extremity. J Hand Surg Am 2010; 35: 1545-53.

21. Janevski B. Arteries of the hands in patients with scleroderma. Diagn Imaging Clinc Med 1986; 55: 262-5.

22. Allanore $\mathrm{Y}$, Seror $\mathrm{R}$, Chevrot A, Kahan A, Drapé JL. Hand vascular involvement assessed by magnetic resonance angiography in systemic sclerosis. Arthritis Rheum 2007; 56: 2747-54.

23. Wang J, Yarnykh VL, Molitor JA, Nash RA, Chu B, Wilson GJ et al. Micro magnetic resonance angiography of the finger in systemic sclerosis. Rheumatology (Oxford) 2008; 47:1239-43.

24. Cervera R, Piette JC, Font J, Khamashta MA, Shoenfeld Y, Camps MT et al. Antiphospholipid syndrome: clinical and immunologic manifestations and patterns of disease expression in a cohort of 1,000 patients. Arthritis Rheum 2002; 46: 1019-27. 
25. Hughes M, Ong V, Anderson M, Hall F, Moinzadeh P, Griffiths B et al. Consensus best practice pathway of the UK Scleroderma Study Group: Digital vasculopathy in systemic sclerosis. Rheumatology (Oxford) 2015; 54: 2015-24.

26. Herrick AL. Diagnosis and management of scleroderma peripheral vascular disease. Rheum Dis Clin North Am 2008; 34:89-114.

27. Allanore Y, Drappe J-L, Reifsnyder T. Angiography. In: Raynaud's Phenomenon. Wigley FM, Herrick AL, Flavahan NA editors. Springer, New York. 2015. p243-52.

28. Herrick AL, Muir L. Raynaud's phenomenon (secondary). Systematic review 1125. BMJ Clinical Evidence. http://clinicalevidence.bmj.com/x/systematicreview/1125/overview.html

29. Wigley FM, Wise RA, Seibold JR, McCloskey, DA, Kujala G, Medsger TA, et al. Intravenous iloprost infusion in patients with Raynaud phenomenon secondary to systemic sclerosis. A multicenter, placebo-controlled, double-blind study. Ann Intern Med. 1994;120:199-206.

30. Pope J, Fenlon D, Thompson A, Shea B, Furst D, Wells GA, et al. lloprost and cisaprost for Raynaud's phenomenon in progressive systemic sclerosis. Cochrane Database Syst Rev 2000; 2:CD000953. 


\section{ACCEPTED MANUSCRIPT}

31. Herrick AL. Management of Raynaud's phenomenon and digital ischaemia. Curr Rheumaol Reports 2013; 15: 303.

32.. Bose N, Chiesa-Vottero A, Chatterjee S. Scleroderma renal crisis. Semin Arthritis Rheum. 2015; 44: 687-94.

33. Steen VD and Medsger TA Jr. Case-control study of corticosteroids and other drugs that either precipitate or protect from the development of scleroderma renal crisis. Arthritis Rheum. 1998; 41: 1613-9.

34. Zhou AY, Muir L, Harris J, Herrick AL. The impact of magnetic resonance imaging in early diagnosis of hand osteomyelitis in patients with systemic sclerosis. Clin Exp Rheumatol. 2014; 32(6 Suppl 86):S-232.

35.. Abou-Raya A, Abou-Raya S, Helmii M. Statins: potentially useful therapy of systemic sclerosis-related Raynaud's phenomenon and digital ulcers. J Rheumatol 2008; 35: 1801-8.

36. Reilly IA, Roy L, Fitzgerald GA. Biosynthesis of thromboxane in patients with 


\section{ACCEPTED MANUSCRIPT}

systemic sclerosis and Raynaud's phenomenon. Br Med J (Clin Res Ed). 1986; 292: 1037-9.

37. Pamuk GE, Turgut B, Pamuk ON, et al. Increased circulating plateletleucocyte complexes in patients with primary Raynaud's phenomenon and Raynaud's phenomenon secondary to systemic sclerosis: a comparative study. Blood Coagul Fibrinolysis. 2007; 18: 297-302.

38. Korn JH, Mayes M, Matucci-Cerinic M, Rainisio M, Pope J, Hachulla E et al. Digital ulcers in systemic sclerosis: prevention by treatment with bosentan, an oral endothelin receptor antagonist. Arthritis Rheum. 2004; 50: 3985-93.

39. Matucci-Cerinic M, Denton CP, Furst DE, Mayes MD, Hsu VM, Carpentier P et al. Bosentan treatment of digital ulcers related to systemic sclerosis: results from the RAPIDS-2 randomised, double-blind, placebo-controlled trial. Ann Rheum Dis. 2011; 70: 32-8.

40. Muir L. Surgical management. In: Wigley FM, Herrick AL, Flavahan NA editors. Raynaud's Phenomenon: A guide to pathogenesis and treatment. Springer, New York. 2015. p361-72.

41. Kotsis SV, Chung KC. A systematic review of the outcomes of digital 


\section{ACCEPTED MANUSCRIPT}

sympathectomy for treatment of chronic digital ischemia. J Rheumatol 2003; 30: 1788-92.

42. Bogoch ER, Gross DK. Surgery of the hand in patients with systemic sclerosis: outcomes and considerations. J Rheumatol. 2005; 32: 642-8.

43. Momeni A, Sorice SC, Valenzuela A, Fiorentino DF, Chung L, Chang J. Surgical treatment of systemic sclerosis-is it justified to offer peripheral sympathectomy earlier in the disease process? Microsurgery. 2015; 35: 441-6.

44. Neumeister MW. Botulinum toxin type A in the treatment of Raynaud's phenomenon. J Hand Surg Am. 2010; 35: 2085-92.

45. Neumeister MW. The role of botulinum toxin in vasospastic disorders of the hand. Hand Clin. 2015; 31: 23-37.

46. Iorio ML, Masden DL, Higgins JP. Botulinum toxin: A treatment of Raynaud's phenomenon: a review. Sem Arthritis Rheum. 2012; 41: 599-603.

47. Merritt WH. Role and rationale for extended periarterial sympathectomy in the management of severe Raynaud syndrome: techniques and results. Hand Clin. 2015; 31: 101-20. 
48. Bank J, Fuller S, Henry G, Zachary LS. Fat grafting to the hand in patients with Raynaud phenomenon: a novel therapeutic modality. Plast Reconstr Surg. 2014; 133: 1109-18. 


\section{ACCEPTED MANUSCRIPT}

Table 1. Contributory causes to critical digital ischemia in patients with SSc

\section{SSc Related}

(affecting

microvessels and

arteries)

Vasculitis (e.g. overlap syndromes with

rheumatoid arthritis, SLE and Sjögren's)

Cryoglobulinaemia

\section{Non-SSc Related}

angiopathy Proximal large vessel disease

and digital Smoking

Thrombophilia: Congenital and acquired

(e.g. antiphospholipid syndrome)

Embolic disease: thrombotic and septic emboli (rare)

Paraproteinaemia

Paraneoplastic phenomenon 

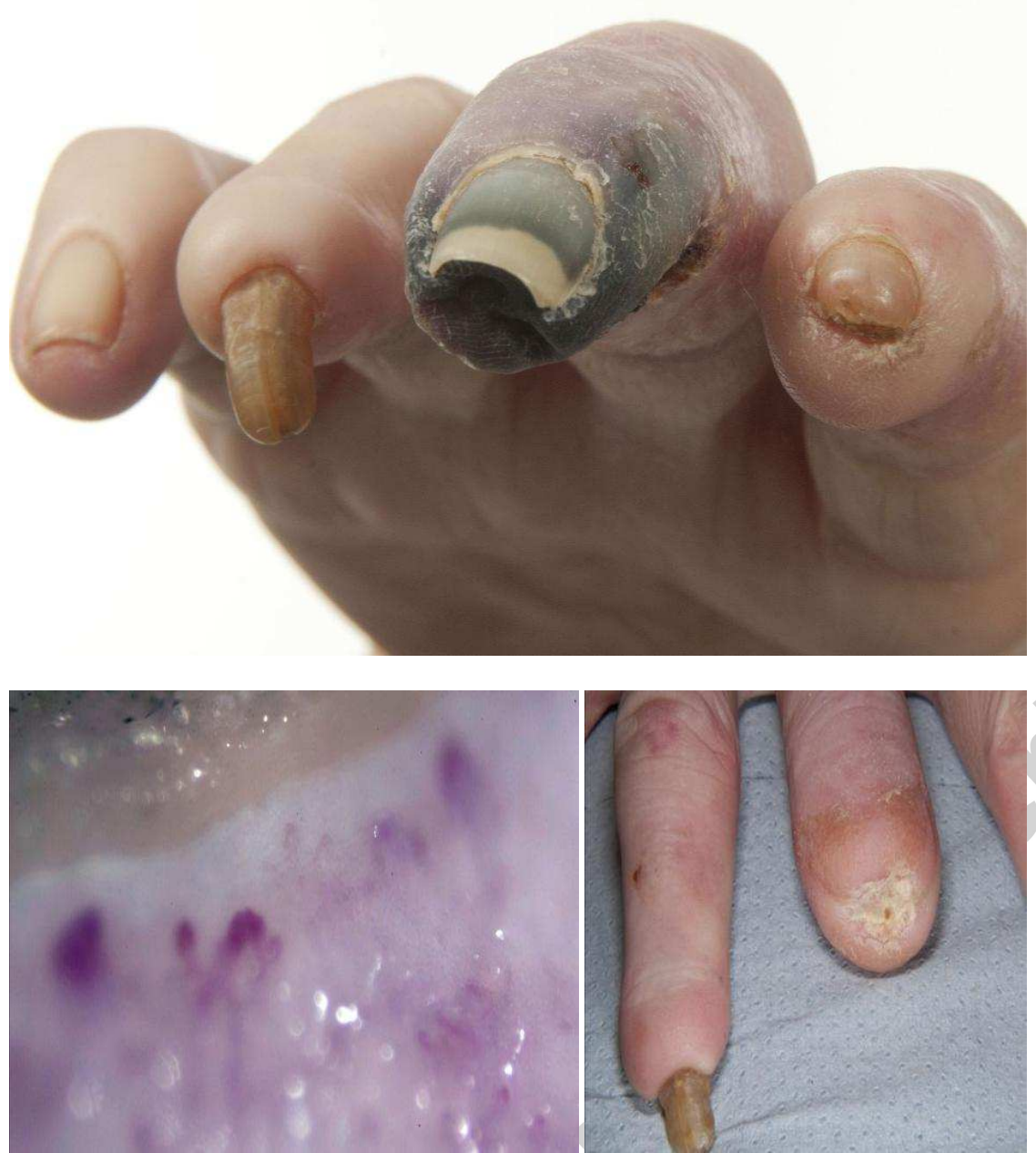

Figure 1. Patient images: a) Critical digital ischemia of the right middle finger, b) contemporaneous nailfold capillaroscopy demonstrating giant capillaries and areas of avascularity, c) post right middle finger amputation 


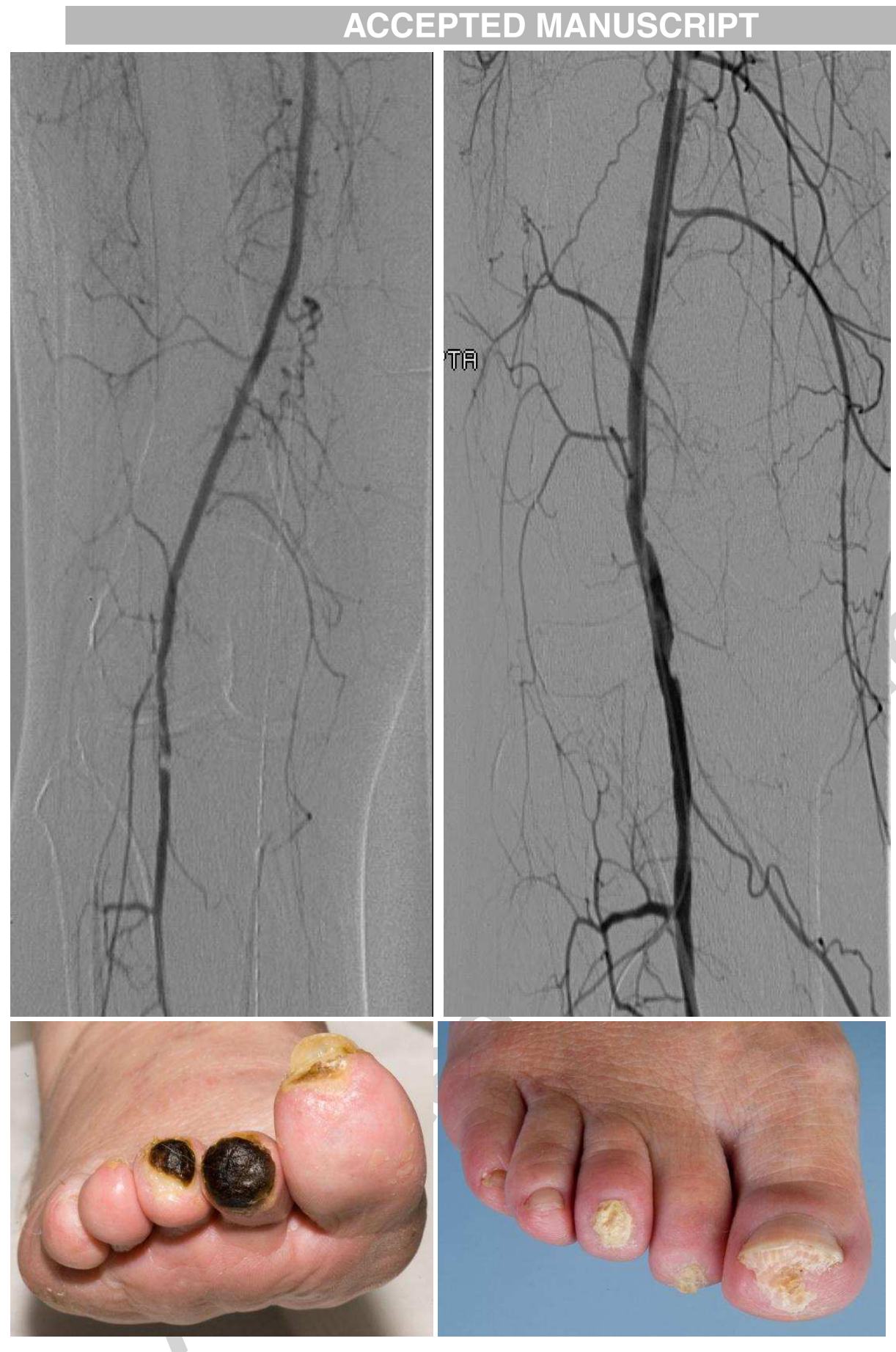

Figure 2. Patient images: a) angiography demonstrating severe focal stenosis of the popliteal artery at knee joint level (white arrow), b) postangioplasty images showing substantial improvement with minor residual popliteal narrowing persisting (white arrow), c) initial demarcation of the critically 


\section{ACCEPTED MANUSCRIPT}

ischemic areas followed by $d$ ) resolution of toe ischemia and ulceration postangioplasty

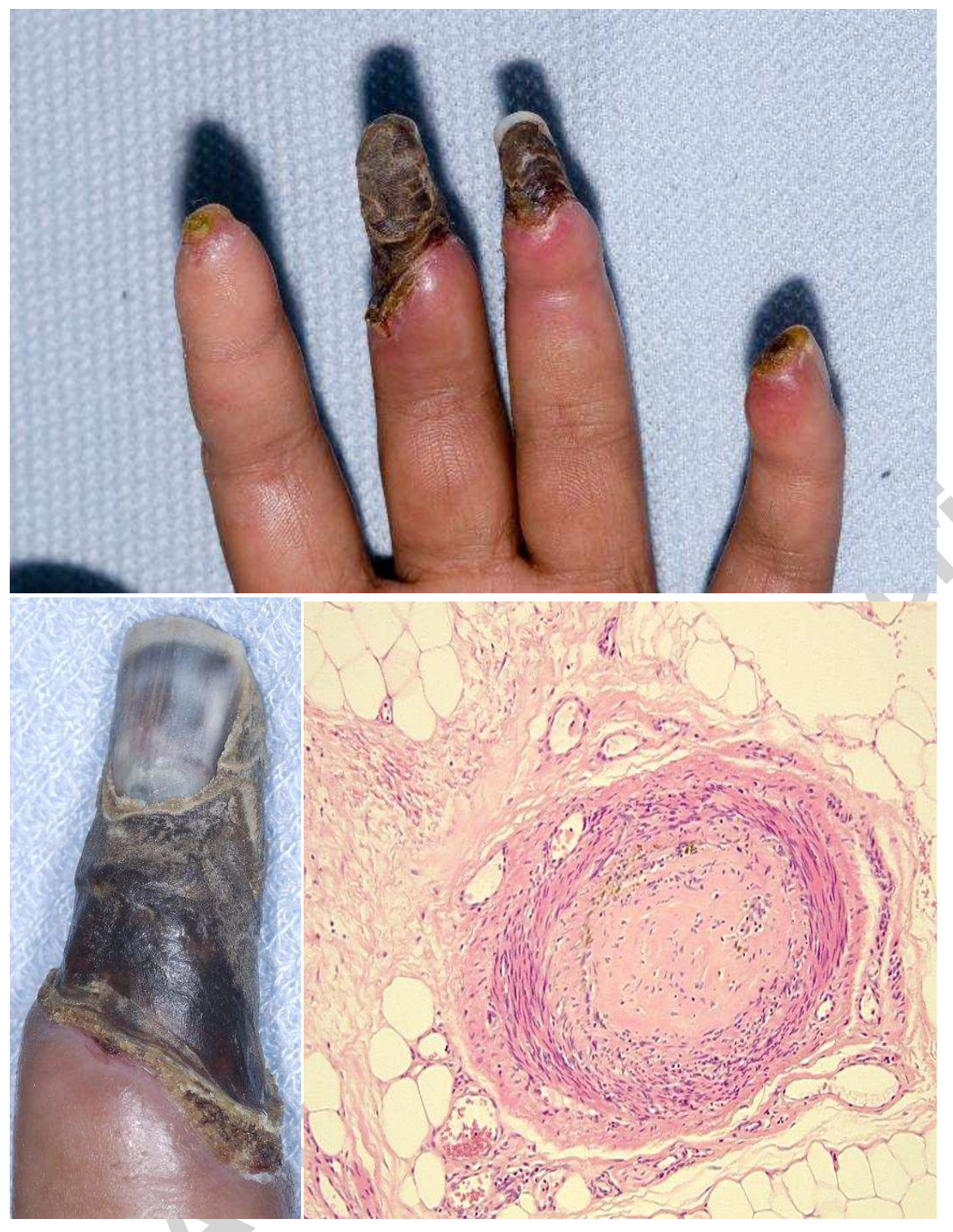

Figure 3. Patient images: a) critical digital ischemia of left middle, ring and little fingers, b) mummification of the middle finger due to critical digital ischemia, c) histology of the amputation specimen showing intimal sclerosis of the digital artery (typical of systemic sclerosis-related angiopathy) with complete occlusion. There was 


\section{ACCEPTED MANUSCRIPT}

no evidence of vasculitis. (Figure courtesy of Professor Anthony Freemont, Manchester, UK)
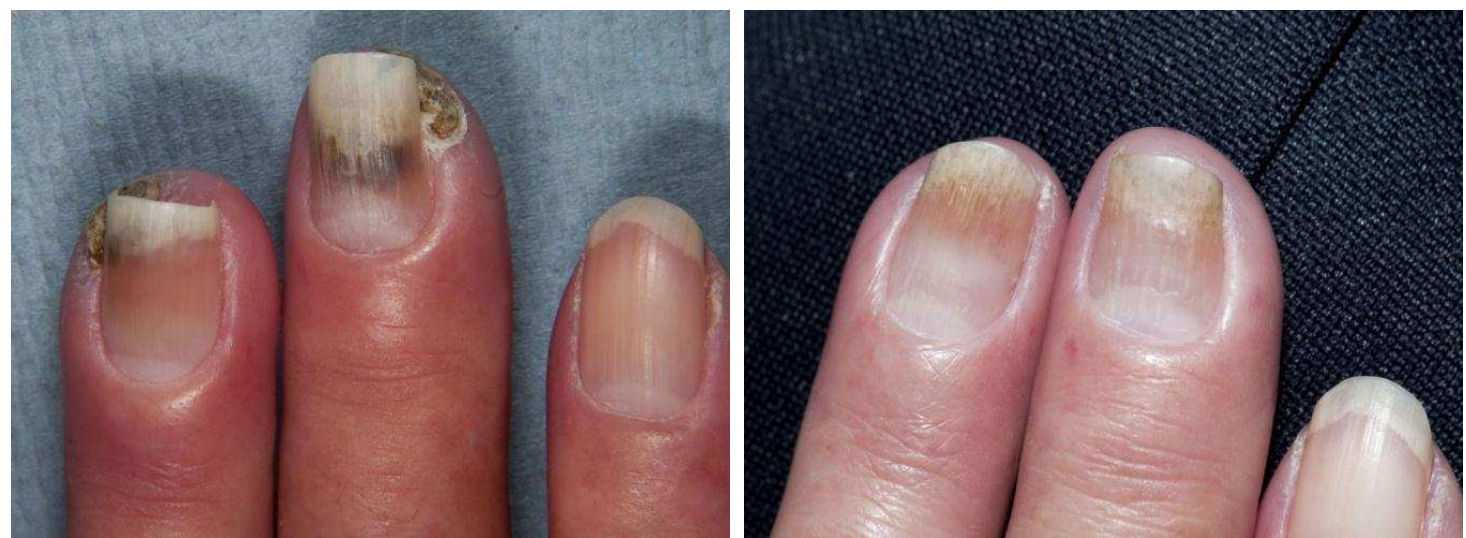

Figure 4. Patient images: a) Left middle and ring finger critical ischemia and ulceration on admission, b) improvement with minimal tissue loss following three months' anticoagulation with warfarin 


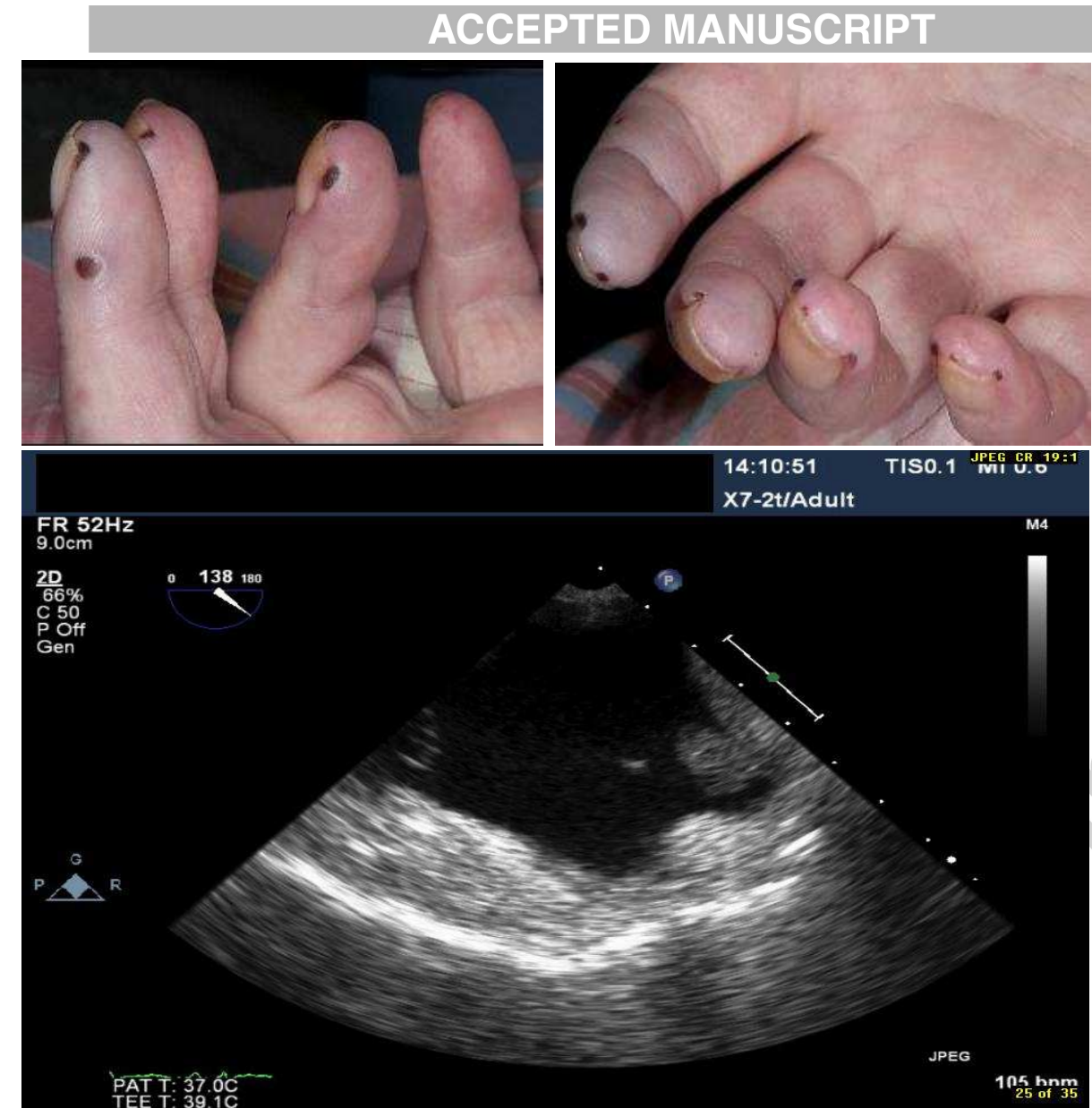

Figure 5. Patient Images: a) Left and b) right hand digital infarcts on presentation, c) 2D echocardiogram showing central venous line (small arrow) and thrombus (large arrow) adjacent to the right atrial appendage (Figure courtesy of Dr Peter Woolfson, Salford, UK) 